Flier, A. Ia. (2017) Teoriia kul'tury: opyt generalizatsii. Kul'tura kul'tury, no. 4 [online] Available at: http://cult-cult.ru/ the-theory-of-culture-a-new-generalization/ (access date: 10.2.2018). (In Russ.).

Flier, A. Ia. (2018) Ideologicheskaia funktsiia kul'turnoi politiki. Znanie. Ponimanie. Umenie, no. 1, pp. 57-64. DOI: 10.17805/zpu.2018.1.5 (In Russ.).

Submission date: 12.12 .2018$.

Флиер Андрей Яковлевич — доктор философских наук, профессор, главный научный сотрудник Российского научно-исследовательского института культурного и природного наследия им. А. С. Аихачева. Адрес: 129366, Россия, г. Москва, ул. Космонавтов, д. 2. Тел.: +7 (495) 686-13-19. Эл. aspec: andrey.flier@yandex.ru

Flier Andrey Yakovlevich, Doctor of Philosophy, Professor, Chief Research Fellow, Likhachev Russian Research Institute for Cultural and Natural Heritage. Postal address: 2, Kosmonavtov St., Moscow, Russian Federation, 129366. Tel.: +7 (495) 686-13-19. E-mail: andrey.flier@yandex.ru

DOI: $10.17805 /$ zpu.2019.4.12

\title{
Сложность культуры и сложность в культуре
}

\author{
П. В. ОПОЛЕВ \\ СИБИРСКИЙ ГОСУДАРСТВЕННЫЙ АВТОМОБИЛЬНО-ДОРОЖНЫЙ УНИВЕРСИТЕТ
}

Человеческая история и культура демонстрируют возрастание разнообразных видов сложности. Вместе с тем представления о сложности культуры разработаны недостаточно. В рамках статьи произведена реконструкция представлений о сложности в известных моделях культуры (культура как организм, механизм, текст, дискурс, система).

Культурное многообразие вырастает из разнообразия культурных форм, раскрывающихся в историческом процессе. В рассмотренных концепциях культуры рефлексируются характерные особенности культурной сложности. Отмечается, что сложность культуры плохо поддается генерализирующим методам, носит относительный характер, что не мешает в рамках различных подходов выделять объективные и субъективные критерии сложности культуры.

Представления об универсальной сложности культуры не могут быть ценностно-нейтральными. В ряде проанализированных концепций, идея универсальной культуры рассматривается как форма этноцентризма, предполагающая, что сложность культуры может быть выявлена только по сравнению с эталоном - западноевропейской культурой. При этом сложные социокультурные практики, не имеющие аналога в европейской традиции, в контексте такого подхода будут рассматриваться как признак ее примитивности. В настоящее время сложность культуры получает свою интерпретацию в рамках системного подхода и концепций синергетического типа, что позволяет выделить коэволюционные стратегии, фиксирующие связь между природой, человеком и культурой.

Ключевые слова: культура; сложность культуры; концепция культуры; теория культуры; культурология; понятие культуры

\section{ВВЕАЕНИЕ}

Существующие концепции культуры демонстрируют разнообразие исторически сложившихся интерпретаций культуры. Исходные единицы анализа культуры варьируются в широких пределах: от образа культуры как органической или механистической целостности, культуры как ценностно-смысловой сферы, формы самореали- 
зации духа до описания культуры как текста, многообразия дискурсов. Все подходы к культуре косвенно высказываются о сложности культуры, которая тем не менее долгое время не выступала в качестве предмета для самостоятельного изучения. Никто не полагал, что культура проста, однако же сложность культуры мыслилась преимущественно интуитивно.

Проблематика сложности культуры не относится к числу разработанных проблем, ее актуализация связана с развитием концепций синергетического типа и «наук о сложном» (complexity theory). По нашему мнению, сложность культуры является важным параметром ее бытия, позволяющим эксплицировать содержательные и формальные аспекты культуры. В отечественных исследованиях понятие «сложность культуры» только получает свое теоретическое осмысление (см., напр.: Пилипенко, 2015: Электронный ресурс). Текстуальная сложность культуры как семиосферы была одним из предметов изучения Ю. М. Аотмана (Иотман, 1998). В известных нам зарубежных исследованиях сложности культуры уделяется несколько больше внимания (см., напр.: Bargendordff, 2009; Chao, Moon, 2005; Hodge, 2007: Электронный ресурс; Vegvari, 2013: Электронный ресурс).

Концептуализация понятия «сложность культуры» позволяет описать объективные характеристики культуры, наметить отличия между культурами, зафиксировать антропологические особенности сложности (см., напр.: Ополев, 2018), складывающиеся под воздействием различных форм разворачивания сложности (см., напр.: Ополев, 2015).

Целью данной статьи является осмысление проблем определения культурной сложности, концептуализация критериев измерения сложности культуры. В статье прослеживается диалектическая связь между объектным и субъектным подходами в оценке сложности культуры, отмечается роль количественных и качественных критериев в характеристике ее сложности. Новизна данного исследования определяется использованием концепта «сложность» для рецепции сложившихся и складывающихся моделей культуры.

Осмысление сложности и усложнения как антропокультурного феномена составляет предмет научного интереса автора данной статьи. Этот подход исходит из того, что сложность как феномен культуры задана не только объективными структурными особенности культуры, но и ее антропологическими параметрами: деятельностной активностью субъекта, его способностями к преобразованию действительности, осмыслению результатов деятельности и др.

\section{МЕХАНИСТИЧЕСКИЕ И ОРГАНИСТИЧЕСКИЕ ИНТЕРПРЕТАЦИИ САОЖНОСТИ КУАБТУРЫ}

Различия между культурами обращали на себя внимание начиная с Античности. Работы древних историков содержат обширный этнографический материал, позволяющий получить некоторые представления о культурных особенностях, материальных различиях между культурами. Общим местом для многих сочинений античных историков является дихотомия «цивилизация - варварство». Цивилизация противопоставляется примитивному варварскому состоянию. При этом цивилизация указывает как на разнообразие - сложность материальной культуры, так и на высокие достижения культуры духовной.

Популярными аналогиями для познания культуры и общества являются организм и механизм. Усложнение культуры может быть описано как продолжение процесса 
объективного усложнения природы. В работах И. Г. Гердера человек и культура представляют собой естественное продолжение органической природы (Гердер, 2013: 23). Выстраивание культурного многообразия в одну эволюционную линию с природой соответствует и подходу Г. В. Ф. Гегеля. Органицизм в толковании социокультурной действительности подчеркивает такие черты, присущие любому организму, как слаженность его частей, целостность, упорядоченность, иначе говоря, сложность. Как отмечает А. А. Малиновский, «общество по своей сложности и типу организации приближается к наиболее высокоразвитым организмам, без их, однако, заранее заданной ограниченности развития» (Малиновский, 2000: 79). Усложнение рассматривается как естественный процесс, аналог биологического развития, в котором рождение, достижение зрелости неизбежно заканчиваются смертью.

Представления о логике усложнения общечеловеческой культуры вырастают из эволюционных представлений, сформировавшихся в естествознании. Сложность культуры в рамках последовательного социального эволюционизма (Г. Спенсер, $\Lambda$. Уайт и др.) предполагает конечную форму культурной сложности, которая неразрывно связана с западноевропейской цивилизацией. В общем-то, при такой постановке вопрос о концептуальном оформлении культурной сложности смещается в несколько иную плоскость. Сложность отдельно взятой культуры является отражением сложности одной-единственной культуры (зачастую европейской) на определенном этапе ее развития. Сложность западноевропейской цивилизации выступает в качестве эталона для всей палитры культурного многообразия.

Типологический подход к культуре позволяет сложность культуры рассмотреть через идею множественности. Сложность культуры в таком случае может быть описана как проявление ее уникальности. Типологические концепции культур исходят из идеи многообразия культур, каждая из которых обладает целостной организацией (как внутренней, так и внешней), имеющей инвариантные проявления, которые тем не менее могут раскрываться уникальным образом.

В работах О. Шпенглера усложнение культур видится как процесс синхронный, объективный и закономерный, подчиненный логике развития живого, исторического организма (проходящего этапы детства, юности, зрелости, увядания) или безличным природным циклам (весна, лето, осень, зима). Аанные этапы можно интерпретировать и как усложнение субъекта, становление сознания (мифологического, религиозного, метафизического, научного), в котором последовательно находит свое выражение культурная форма. На этапе умирания культура превращается в цивилизацию - завершающую форму бытия культуры. В этом случае можно сказать, что естественную сложность организма, обладающего душой, О. Шпенглер противопоставляет искусственной сложности механизма, мертвой рациональности. Культура является выражением природной, естественной сложности, в то время как цивилизация - выражением сложности искусственной.

Органистические метафоры культуры находят свое развитие в концепции «естественной системы истории», в натуралистическом подходе Н. Я. Аанилевского (Аанилевский, 2008: 88-113). Изучение типологии живых организмов позволило ему прийти к мысли о том, что известное разнообразие органических форм не имеет универсального основания и предполагает своеобразие, уникальность, самобытность путей их становления и развития. Совершенство не зависит от типа организации и степени развития живого. Культуры, как и организмы, несоизмеримы, что позволило Н. Я. Аанилевскому создать концепцию культурно-исторических типов развития при разно- 
образии векторов исторического развития человечества. Сложность культуры, исходя из логики его концепции, может быть понята как ее органическое свойство, позволяющее сохранять ее целостность и разнообразие.

В описании цикличного развития культурной целостности в работах К. Н. Аеонтьева мы встречаем дихотомию «простота-сложность» в качестве основания для закона «триединого развития». При этом состояние цветущей сложности занимает промежуточное положение между «первичной простотой» и «вторичным смесительным упрощением». Вместе с тем цветущая сложность не представляет собой умеренное однообразие. Мир культуры - это совокупность полярностей, в котором любая «середина является олицетворением смесительного упрощения. Цветущая сложность при всем натурализме данного понятия у К. Н. Аеонтьева имеет эстетический характер. Как отмечает К. Н. Аеонтьев, «в цветущие эпохи постройки разнообразны в пределах стиля; нет ни әклектического смешения, ни бездарной старческой простоты» (Иеонтьев, 2003: 80). Аанное понятие подчеркивает идею многообразия в единстве, порожденного социально-политическим устройством, иерархически-аристократической структурой общества и др.

\section{ОТ ОБЪЕКТИВНЫХ К СУБЪЕКТИВНЫМ АСПЕКТАМ САОЖНОСТИ КУАБТУРЫ}

Критика европоцентристских установок, линейного эволюционизма, отказ от дихотомии «культура-варварство» актуализируется в работах представителей евразийства. Н. С. Трубецкой критикует идеи общечеловеческой культуры, методологию эволюционизма применительно к культуре, формируя идеи исторического разнообразия и самобытности культурных форм. Общечеловеческая культура уничтожает различия, упрощает своеобразие национальных культур и представляет собой форму завуалированного европоцентризма. Мысль о том, что романо-германская культура есть высший этап развития общечеловеческой культуры, расценивается как вредный предрассудок, которой утрирует культурное многообразие, трактует совершенство культур как степень их приближенности к сложности европейской культуры. Н. С. Трубецкой отмечает, что степень сложности культуры не может быть мерилом прогресса, а критерии объективной сложности культур являются отражением этноцентризма, европейского эгоцентризма, используются как средство для подчеркивания превосходства европейской культуры (Трубецкой, 1995: 80).

Культурная сложность с этих позиций не может быть адекватно осмыслена без субъекта культуры: отдельной личности или целого народа, нации («симфонической личности»). Культурная сложность оказывается заданной антропологическим разнообразием, многообразием «разновременных индивидуаций» субъекта культуры и выражается в самобытной национальной культуре. Эта мысль Н. С. Трубецкого находит свое развитие в работах $\Lambda$. П. Карсавина, в которых раскрывается роль коллективного субъекта, возможность построения «всеедино-стяженной» культуры, образа «культуры-личности» (Карсавин, 1993: 161). Культура как творческий акт духа, «преодоления субъектом хаоса собственных переживаний» (Бицилли, 1995: 11-12) рассматривается в работах П. М. Бицилли. Отрыв культуры от творящего его субъекта, объективация духовной сферы в отдельную сферу ценностей, процессы дегуманизации критикуются в работах Хосе Ортега-и-Гассета (Ортега-и-Гассет, 2002: 231).

Несмотря на критику эволюционизма, сторонниками евразийства в понимании культуры воспроизводятся органистические метафоры, однако организм преимуще- 
ственно трактуется не натуралистически, а, скорее, спиритуалистически. Сложность культуры связывается не с количественным многообразием порождаемых благ или технологий, а с ее качественным состоянием - духовным миром, всеединством, стремлением к абсолютным ценностям. При этом сложность культуры также оказывается заданной субъектом (как отдельным, так и коллективным, «симфоническим субъектом», «соборной личностью»). Можно сказать, что сложность личности становится выражением сложности культуры. Абстрактная сложность общечеловеческой культуры видится как символ упрощения, нивелирования многообразия, которое проявляет себя в реальном бытии культуры.

Критика как эволюционистского, так и морфологического подхода к культуре находит свое выражение в философии культуры М. Вебера. Если цивилизация в подходе О. Шпенглера осмысляется как неизбежное следствие культурного усложнения, принимающего форму цивилизационного упрощения, то М. Вебер говорит о различиях между сложностью культуры и сложностью цивилизации. Культура надбиологична (Вебер, 1999: 74), в отличии от цивилизации. Культуру нельзя осмыслить в терминах прогресса. Усложнение культуры - это заблуждение. С одной стороны, культура, наряду с цивилизацией и социальным движением, представляет собой момент исторического процесса. С другой стороны, культура выходит за границу общезначимого и необходимого в область уникального, неповторимого, исключительного, связанного с индивидуально-личностным переживанием трансцендентного. Сложность культуры в этом случае не может быть измерена и представляет собой форму проявления самобытности любой культуры. При этом М. Вебер также склонен противопоставлять цивилизационную сложность, сопряженную с рационализацией, материально-техническим разнообразием, усилением бюрократизации, и культурную сложность, связанную с идеей души (как специфического ядра культуры) (там же: 39 ).

В работе «Постижение истории» А. Аж. Тойнби рассматривает культуру как один из аспектов цивилизации (наряду с экономическим и политическим), которую он называет в духе современной синергетики динамическими образованиями эволюционного типа. В качестве фактора усложнения цивилизации А. Аж. Тойнби предлагает механизм «вызов-ответ», анализирует опасности чрезмерно благоприятных и неблагоприятных условий развития цивилизации. Критерием цивилизационного развития является дифференциация с последующей интеграцией, в которой усиливается социальная самоорганизация, наблюдается возрастание ее сложности. Цивилизационная сложность способствует преодолению соответствующих вызовов и противопоставляется социальной атомизации.

Развитие материально-технической культуры, по мысли А. Аж. Тойнби, не может быть критерием усложнения, развития цивилизации, что находит у автора соответствующую иллюстрацию на конкретном историко-культурном материале. Качественная сложность культуры в работах А. Аж. Тойнби, ее несводимость к материально-техническому многообразию описывается как в натуралистических («кровь», «лимфа» и др.), так и спиритуалистических терминах ( «душа», «судьба» и др.). Он пишет: «Несоответствие между прогрессом в технике и ростом цивилизации очевидно в тех случаях, когда техника развивалась, а рост цивилизации прекращался и начиналась стагнация. Но нет гармонии и тогда, когда в технике наблюдается застой, а цивилизация продолжает развиваться» (Тойнби, 2010: 241). Ауховная революция, способствующая культурной сложности, далеко не всегда сопровождается заметным усложнением материально-технической базы. 
Особое внимание А. Аж. Тойнби уделяет принципу «этерификации», называя его «законом прогрессирующего упрощения». Аействие этого принципа А. Аж. Тойнби иллюстрирует на примерах развития транспортной системы, техники связи, распространяя действие принципа на общественные подсистемы и специализированные формы культуры.

Образ культуры как организма находится в противоречии с позицией неокантианцев, подчеркивающих отличия культуры от природы, ценности жизни от ценностей культуры. Следуя логике Г. Риккерта, можно сказать, что сложность культуры (в отличие от сложности природы) не может быть удовлетворительно описана генерализирующими методами. И это не позволяет нам говорить об усложнении культуры как о закономерном явлении. Исторически-индивидуализирующий метод позволяет говорить о сложности культуры как ее имманентном свойстве, представляющем собой ее ценностно-смысловое многообразие и охватывающем не только культуру, но и субъекта, ее созидающего (Риккерт, 1998: 37).

\section{САОЖНОСТЬ КУАЬТУРЫ КАК СЕМИОСФЕРЫ}

В рамках структурной антропологии сложность культуры определяется системой значений, знаково-символическим многообразием отражения паттернов мышления. Культура как символическое пространство изучается в работах Э. Кассирера (Кассиpep, 2002: 29). С этих позиций сложность культуры можно интерпретировать как отражение символической формы - языка, который выполняет функцию посредника между духом и природой. Сложность культуры задана способностью человека к символизации. В рамках культурной семиотики аналогией культуры становится текст, который представляет собой форму репрезентации сложных взаимодействий кодовых и знаковых систем самой разной природы. В концепциях лингвистов неклассической философии культуры мы наблюдаем изменения критериев сложности культуры: от языка, текста к многообразию дискурсивных практик.

Сложность имманентна культуре, поскольку культура также оказывается заданной нередуцируемой сложностью знаково-символических систем. Культура демонстрирует нам сложную структуру, многообразие связей и отношений, в которых раскрывается богатство смыслов, «порядков бытия». Языковая сложность косвенно свидетельствует о многообразии отношений человека и действительности. В работе А. Тюрго «Прогресс человеческого разума» отмечается роль языкового разнообразия в «умножении идей до бесконечности» (Тюрго, 1999: 163). Многие лингвисты обращали внимание на связь лексики и деятельности человека, при которой чем более разнообразные виды деятельности используются человеком, тем сложнее и многообразнее его лексика. Сложность культуры как текста - один из предметов изучения Ю. М. Аотмана. Культура рассматривается как сложное иерархическое пространство ( «семиосфера» - в терминах Ю. М. Аотмана), «сложное многоголосие» языков, кодов и смыслов (Иотман, 1998: 22).

Аиалектическая связь усложнения текста с трансформацией медийной реальности и последствия этих процессов для культурной действительности получают осмысление в работах структуралистов и постмодернистов. Зарубежный исследователь Б. Ходж в работе «Революция сложности» отмечает, что «гуманитарный стиль сотplexity, который признает текущую сложность текстов и смыслов, является основным в современных медиа и культурных исследованиях» (Hodge, 2007: Электронный ресурс). По его мнению, в гуманитарных науках проблемы «соmplexity» ассоциируются 
с постструктурализмом, в котором ряд авторов (например, Ж. Аеррида) подчеркивают перманентную сложность текста и процесса смыслопорождения.

В рамках постмодернизма сложность культуры определяется сложностью порождаемых ею текстов, коммуникативным многообразием, включающим и внелингвистические факторы. Множественность текста культуры противопоставляется идее развертывания в истории универсальной культуры. Р. Барт отмечает: «Тексту присуща множественность. Это значит, что у него не просто несколько смыслов, но что в нем осуществляется сама множественность смысла как таковая множественность неустранимая, а не просто допустимая. В Тексте нет мирного сосуществования смыслов - Текст пересекает их, движется сквозь них; поэтому он не поддается даже плюралистическому истолкованию, в нем происходит взрыв, рассеяние смысла» (Барт, 1989: 417).

В работе американского этнопсихолога Г. Триандиса «Культура и социальное поведение» рассматриваются аспекты усложнения культуры. Анализируя работы современников, посвященные культурной и социальной сложности, Г. Триандис отмечает такие критерии культурной сложности, как размер поселения, присутствие письменности, исторических записей, сельского хозяйства, профессиональной специализации, количество профессий, наличие многоуровневой политической и социальной стратификации (Триандис, 2011: 201-204). Сложность культуры, по мнению Г. Триандиса, может быть оценена через способность ее субъектов дифференцировать объекты и события действительности. Сложность культуры, существующей в рамках информационного общества, оказывается заданной разнообразием информации, сложными объектами, системами научных знаний.

\section{СИСТЕМНЫЕ ИНТЕРПРЕТАЦИИ САОЖНОСТИ КУАБТУРЫ}

Поиск адекватных стратегий познания культуры, соразмерных современному миру, способствовал развитию системных интерпретаций культуры. В настоящее время теоретический инструментарий, наработанный в ходе развития системного подхода и концепций синергетического типа, позволяет культуру рассмотреть как сложную систему - множество взаимодействующих друг с другом частей, подсистем с обратной связью. Синергетический подход к культуре вырастает из идеи гомологического подобия порядка в природе и культуре. Такого рода подход находит поддержку в ряде современных исследований.

Образ культуры как системы позволяет нам говорить об объективной сложности культуры. В монографии С. Баргендорффа культура рассматривается как сложная динамическая система (Bargendordff, 2009). По мысли Т. Чао и Г. Муна, сложность культурной системы оказывается заданной количеством информации, которую она содержит, и количеством взаимодействий между элементами культурной системы. Культурная сложность в данной работе рассматривается как «многомерная переменная», позволяющая выделять различные типы культурных взаимодействий (Сhао, Moon, 2009). Сложность культуры в работе К. Вегвари сравнивается со сложностью кодовой базы компьютерной игры. Сложность культуры определяется сложностью используемых инструментов (Vegvari, 2013). Вместо поиска общезначимой оценки культурной сложности предлагается рассматривать ее аспекты: технологическую сложность культуры (заданную количеством видов используемых инструментов и технологий), социальную сложность (заданную уровнями социальной стратификации). 
Образ культуры как сложной, открытой саморазвивающейся системы находит свое развитие в гуманитарных концепциях синергетического типа. Синергетика обнаружила и способствовала концептуализации общих законов функционирования и организации сложных саморазвивающихся систем независимо от их природы. Одновременно с этим стало очевидно, что действие этих законов отличается в антропосоциокультурных системах, обладающих более высоким уровнем сложности, которая оказывается заданной их перекрестным взаимодействием (Каган, 2004: 358).

Многообразие концепций культуры, рецепций культурного усложнения вырастает из сложности культуры. Представленные исторические аналогии культуры (организм, механизм, текст, дискурс и т. А.) сообщают не только о сложности самой культуры, но и обобщают представления о сложности, сложившейся в западноевропейской культуре. Развитие естествознания (особенно биологии и механики) стимулировало перенос механистических и органистических метафор на общество, культуру и человека.

Мы полагаем, что сложность культуры и ее особенности могут быть реконструированы через многообразие подходов и методов познания культуры. В работах Э. Морена сложность рассматривается не только как проблема объекта, но и метода, используемого для получения знания об объекте (Морен, 2005: 46). Эта мысль относится и к сложности культуры. Сложность культуры не может быть удовлетворительно рассмотрена как абстракция, она требует обращения к конкретно-историческим типам культуры, что находит свое подтверждение в сравнительно-историческом методе познания культуры. Культурное многообразие вырастает из разнообразия культурных форм, раскрывающихся в историческом процессе. Сложность культуры с позиции методологии функционализма возможно интерпретировать как доступное многообразие поведенческих актов - динамическую совокупность образцов деятельности, поведения. Сторонники неоэволюционизма в качестве критерия усложнения культуры мыслят организованность культурной жизни, которая проявляется в адаптации человека к окружающей среде.

Морфологическое разнообразие культур трудно выявить из какого-то универсального критерия, свести к количественным параметрам: количеству технологий, инструментов, социальных ролей, стратификационных уровней и т. А. В контексте теории информации в качестве критерия сложности культуры можно рассмотреть объемы порождаемой культурой информации. Образ культуры как организма позволяет говорить как об универсальной сложности общечеловеческой культуры (все организмы сложны, обладают слаженностью элементов, упорядоченностью, целостностью), так и об уникальной сложности каждой отдельной культуры (подобно организму, культуры внутренне дифференцированы, разнообразны, несоизмеримы). Эволюционный подход к культуре позволил наметить диалектику усложнения и упрощения в существовании культуры. Вместе с тем сложность культуры плохо поддается генерализирующим методам. Многообразие культурно-исторического материала, незавершенность исторического процесса не дают выявить универсальные, общезначимые критерии системной сложности культуры.

\section{РЕЦЕПЦИИ САОЖНОСТИ \\ В ОТЕЧЕСТВЕННОЙ НАУКЕ И ФИАОСОФИИ}

Историография проблем сложности и усложнения культуры требует самостоятельного изучения. Условно можно выделить несколько подходов к сложности куль- 
туры, актуальных в настоящее время. Первый подход связан с развитием концепций синергетического типа, глобального эволюционизма и использованием концепта «самоорганизация» применительно к социально-гуманитарному знанию (Аршинов, 2013; Баксанский, 2013; Князева, 2015; Назаретян, 2013; Пилипенко, 2015: Электронный ресурс и др.). Культурная сложность осмысляется в контексте представлений о коэволюции, процессов упорядочивания и дезорганизации, взаимодействия биотических и абиотических факторов. В общих чертах представления о сложности в рамках данного подхода совпадают с идеями «парадигмы сложности» (theories of complexity), разрабатываемыми в зарубежных исследованиях. Сложность культуры в рамках данного подхода вырастает из ее системных свойств. Второй подход к сложности культуры можно назвать «антропологическим» (Каган, 2018 и др.). Сложность культуры в рамках данного подхода варьирует в определенных пределах сложность самого человека. Вопрос об инвариантных структурных основах человеческой природы возвращает нас к классическим проблемам философской антропологии. Третий подход к исследованию сложности культуры мы предлагаем называть «антропокультурным» (Богатая, 2016; Аонникова, 2011; Оводова, 2016) и др.).

\section{В ПОИСКАХ КРИТЕРИЯ КУАБТУРНОЙ САОЖНОСТИ}

Рассмотренные концепции культуры не исчерпывают палитру возможных критериев оценки культурной сложности. С одной стороны, представления о культурной сложности растворены в обширном материале о культуре. С другой стороны, взгляды на культурную сложность обогащаются по мере культурных трансформаций. Поэтому воздержимся от окончательных суждений. Проблематика все еще требует обстоятельного обсуждения.

Ценность и новизна предложенной реконструкции связана с тем, что она не исчерпывает, а, скорее, вскрывает ряд формально-логических и диалектических противоречий в оценке культурной сложности. Культура не может быть простой. Многообразие культурных феноменов, историческое разнообразие культур также не требуют дополнительного обоснования. С логической стороны оценка культурной сложности носит характер сравнительного обоснования: почему одна культура сложнее, чем Аругая?

Абсолютное обоснование сложности культуры вряд ли возможно, поскольку поставленная проблематика вырастает из культурного многообразия. Все культуры сложны. Существует «несократимая сложность» культуры, переступая которую, она не может воспроизводить свою структуру. Однако поиск универсальных критериев культурной сложности принимает односторонние формы, не может быть ценностно-нейтральным, о чем мы уже говорили. Абсолютное обоснование культурной сложности получает оттенок этноцентризма. Вместе с тем это не означает, что отсутствуют критерии объективной сложности культуры. Мы полагаем, что основное диалектическое противоречие состоит в том, что сложность культуры объективна, но не может быть удовлетворительно описана без учета сложности субъекта. В свою очередь, актуализация сложности субъекта (индивидуального или коллективного), раскрытие его потенциальных возможностей вырастают из характера сложности самой культуры. При этом культура может обладать высокой сложностью культурной специализации, но низким уровнем системной сложности, быть в «плену» собственной специализации. 
Полагаем, что нельзя обойтись без видения гипотетически возможных критериев для оценки культурной сложности. Отчасти авторское видение проблемы представлено в реконструкции и интерпретации имеющихся концепций культуры, поэтому не будем дублировать сказанное, остановимся на неозвученных критериях оценки культурной сложности.

Сложность культуры может быть оценена через ее способность к созданию гибридных культурных форм: чем больше культура способна к адаптации и межкультурному взаимодействию, тем она сложнее. Неспособность к межкультурной интеграции в таком случае свидетельствует о ее примитивности. Сложность культуры можно оценить через количество необходимых к освоению субъектами социальных ролей, возможностей для социальной мобильности, многообразию социокультурных идентичностей, порождаемых культурой. Несмотря на маргинальность некоторых предположений, полагаем, что такого рода критерии возможны, однако их эвристический потенциал, научная жизнеспособность требуют самостоятельного обсуждения. Считаем, что возможно использовать комплексный подход, учитывающий количественную сложность культуры, поддающуюся вычислительной оценке, и качественные методы. Это вскрывает междисциплинарный характер проблемы культурной сложности, которая вместе с тем требует и философской рефлексии.

\section{ЗАКАЮЧЕНИЕ}

Рассматривая рецепции культуры в представленных концепциях, мы наблюдаем переход от оценки порождаемого культурой объективного материально-технического разнообразия к рефлексии разнообразия духовной культуры. Сложность культуры как организма описывается с помощью как натуралистических (рост, взросление, кровь, лимфа и т. А.), так и спиритуалистических метафор (душа, дух и т. А.). Культурное усложнение рассматривается как умножение многообразия. Возрастание однородности и единообразия, напротив, видится симптомом деградации - упрощения. В качестве критериев сложности культуры рассматриваются не только ее материально-техническое разнообразие, но и многообразие духовной сферы. Естественная сложность культуры противопоставляется искусственной-механической сложности цивилизации. Объективная сложность материальных систем, инструментов, технологий, порождаемых культурой, противопоставляется ценностно-смысловому многообразию духовной культуры. Сложность культуры предлагается также измерять ее нематериальными әлементами, связывать с деятельностью субъекта (в том числе, и коллективного). В этом случае антропологическая сложность становится выражением сложности культуры.

Многообразие философских моделей культуры соответствует ее сложности. В настоящее время сложность культуры описывается как следствие ее системных свойств. Понятие «система» снимает противоречия между представлениями о слаженности частей организма и механизма, искусственными и естественными системами. Такого рода подход к описанию сложности фундирован достижениями естественных наук. В рамках системного подхода, кибернетики, синергетики и глобального эволюционизма формируется идея коэволюции, позволяющая снять противоречия, порожденные спецификой сложности природного и социокультурного порядка. Тем не менее полагаем, что выводить культурное многообразие из системных свойств культуры, значит, существенно обеднять наши представления о ней. По крайней мере сложность культур не может быть удовлетворительно объяснена исключительно исходя из си- 
стемных свойств природных объектов. Принципиальная авторская позиция состоит в том, что сложность культуры и сложность в культуре связаны с человеком. Требуется конструирование гуманитарной концепции сложности, которая бы вырабатывала новые стратегии отношения человека с действительностью и учитывала сложность не только культуры, но и самого человека.

\section{СПИСОК АИТЕРАТУРЫ}

Аршинов, В. И. (2013) Наблюдатель сложности в контексте парадигмы постнеклассической рациональности // Философия науки. № 1. Т. 18. С. 48-61.

Баксанский, О. Е. (2013) Коэволюционное мышление в контексте конвергентных технологий: от биологии к культуре // Философия и культура. №9 (69). С. 1307-1313.

Барт, Р. (1989) Избранные работы: Семиотика. Поэтика. М. : Прогресс. 616 с.

Богатая, $\Lambda$. Н. (2016) Гуманитарная сложность в контексте некоторых актуальных понятий современной культуры // Інтегративна Антропологія. № 2. С. 4-9.

Бицилли, П. М. (1995) Элементы средневековой культуры. СПб. : Мифрил. 264 с.

Вебер, А. (1999) Избранное: Кризис европейской культуры. СПб. : Университетская книга. 565 с.

Гердер, И. Г. (2013) Идеи к философии истории человечества. СПб. : Центр гуманитарных инициатив. $760 \mathrm{c.}$

Аанилевский, Н. Я. (2008) Россия и Европа. М. : Институт русской цивилизации. 816 с.

Аонникова, И. А (2011) Культурогенная сущность социальной самоорганизации. Одесса : Печатный дом. 280 с.

Каган, М. С. (2004) О синергетическом подходе к построению онтологии // Синергетическая парадигма. Когнитивно-коммуникативные стратегии современного научного познания / отв. ред. А. П. Киященко. М. : Прогресс-Традиция. 560 с. С. 350-367.

Каган, М. С. (2018) Человек в теории культуры. Избранные труды : учеб. пособие для вузов. М. : Издательство Юрайт. 195 с.

Карсавин, А. П. (1993) Философия истории. СПб. : Комплект. 350 с.

Кассирер, Э. (2002) Философия символических форм. Язык. М. ; СПб. : Университетская книга. Т. 1. 272 с.

Князева, Е. Н. (2015) Инновационная сложность: методология организации сложных адаптивных и сетевых структур // Философия науки и техники. Т. 20. № 2. С. 50-69.

Аеонтьев, К. Н. (2003) Храм и Церковь. М. : ООО «Издательство АСТ». 636 с.

Иотман, Ю. М. (1998) Структура художественного текста. СПб. : Искусство-СПб. 704 с.

Малиновский, А. А. (2000) Тектология. Теория систем. Теоретическая биология. М. : Эдиториал УРСС. 448 с.

Морен, Э. (2005) Метод. Природа Природы. М. : Прогресс-Традиция. 464 с.

Назаретян, А. П. (2013) Нелинейное будущее. М. : МБА. 440 с.

Оводова, С.Н. (2016) Антропокультурная реальность: от парадокса к проекту. Омск : Иза-во Ом. гос. ун-та. 190 с.

Ополев, П. В. (2015) В поисках субъективной сложности: от логоса к логеме // Вестник Омского государственного педагогического университета. Гуманитарные исследования. № 4 (8). C. $17-21$.

Ополев, П. В. (2018) Проблемы определения антропокультурной сложности // Гуманитарный вестник. № 10 (72). С. 1-15. DOI: 10.18698/2306-8477-2018-10-561

Ортега-и-Гассет, Х. (2008) Восстание масс. Аегуманизация искусства. Бесхребетная Испания. М. : АСТ. 347 с.

Пилипенко, А. А. (2015) Эпистема сложности и ее проявления в культуре [Электронный ресурс] // Культура культуры. № 2 (6). URL: http://cult-cult.ru/episteme-of-complexity-and-itsmanifestation-in-culture/ (дата обращения: 27.04.2019).

Риккерт, Г. (1998) Науки о природе и науки о культуре. М. : Республика. 413 с. 
Тойнби, А. (2010) Постижение истории / пер. с англ. Е. А. Жаркова. М. : Айрис-пресс. 640 с.

Триандис, Г. К. (2011) Культура и социальное поведение. М. : Форум. 384 с.

Трубецкой, Н. С. (1995) История. Культура. Язык. М. : Прогресс. 799 с.

Тюрго, А. (1999) Прогресс человеческого разума // Философия и общество. № 3. С. 160-167.

Bargendordff, S. (2009) Simple Lives, Cultural Complexity. Rethinking Culture in Terms of Complexity Theory. Lanham MD: Lexington Books. 188 p.

Chao, T. G., Moon, H. (2005) The cultural mosaic: a metatheory for understanding the complexity of culture // Journal of Applied Psychology. Vol. 90. №60. P. 1128-1140.

Hodge, B. (2007) The Complexity Revolution [Электронный ресурс]// A Journal of Media and Culture. Vol. 10. URL: http://journal.media-culture.org.au/0706/01-hodge.php (дата обращения: 27.04.2019).

Vegvari, C. (2013) What is cultural complexity? [Электронный ресурс] // Evolution \& cognition. URL: https://evolutioncognition.wordpress.com/2013/02/11/what-is-cultural-complexity/ (дата обращения: 27.04.2019).

Аата поступления: 16.05.2019 2.

\section{THE COMPLEXITY OF CULTURE \\ AND COMPLEXITY IN CULTURE \\ P. V. OPOLEV}

\section{Siberian State Automobile AND HighWAy UnIVERSITY}

Human history and culture show an increasing variety of complexity. However, the concept of cultural complexity is not well developed. Within the framework of the article, the author reconstructs the notions of complexity in the known models of culture (culture as an organism, mechanism, text, discourse, system).

Cultural diversity grows out of the diversity of cultural forms revealed in the historical process. In the considered concepts of culture the characteristic features of cultural complexity are reflected. It is noted that the complexity of culture is difficult to generalize, is relative, which does not prevent determining objective and subjective criteria of the complexity of culture within the framework of various approaches.

Ideas about the universal complexity of culture cannot be value-neutral. In a number of the analyzed concepts, the idea of a universal culture is considered as a form of ethnocentrism, suggesting that the complexity of culture can be revealed only in comparison with the standard - Western European culture. At the same time, complex socio-cultural practices that have no analogue in the European tradition, in the context of this approach, will be considered as a sign of its primitiveness.

Currently, the complexity of culture receives its interpretation in the context of a systematic approach and concepts of synergetic type, which allows us to identify co-evolutionary strategies that fix the relationship between nature, man and culture.

Keywords: culture; complexity of culture; concept of culture; cultural theory; cultural studies; notion of culture

\section{REFERENCES}

Arshinov, V. I. (2013) Nabljudatel' slozhnosti v kontekste paradigmy postneklassicheskoj racional'nosti. Filosofija nauki. no 1. Vol. 18. Pp. 48-61. (In Russ.)

Baksanskij, O. E. (2013) Kojevoljucionnoe myshlenie v kontekste konvergentnyh tehnologij: ot biologii k kul'ture. Filosofija i kul'tura. 2013. no. 9 (69). Pp. 1307-1313. (In Russ.).

Barthes, R. (1989) Izbrannye raboty: Semiotika. Poetika. Moscow, Pogress Publ. 616 p. (In Russ.)

Bogataja, L. N. (2016) Gumanitarnaja slozhnost' v kontekste nekotoryh aktual'nyh ponjatij sovremennoj kul'tury. Integrativna Antropologija. no 2. Pp. 4-9. (In Russ.) Russ.)

Bitsilli, P. M. (1995) Elementy srednevekovoi kul'tury. St.-Petersburg, Mifril Publ. 264 p. (In 
Weber, A. (1999) Izbrannoe: Krizis evropeiskoi kul'tury. St.-Petersburg, Universitetskaia kniga Publ. 565 p. (In Russ.)

Herder, I. G. (2013) Idei k filosofii istorii chelovechestva. St.-Petersburg, Centr gumanitarnyh iniciativ. 760 p. (In Russ.)

Danilevskij, N. Ja. (2008) Rossija i Evropa. Moscow, Institut russkoj civilizacii. 816 p. (In Russ.)

Donnikova, I. A (2011) Kul'turogennaja susbbnost' social'noj samoorganizacii. Odessa: Pechatnyj dom. 280 p. (In Russ.)

Kagan, M. S. (2004) O sinergeticheskom podkhode k postroeniiu ontologii. Sinergeticheskaia paradigma. Kognitivno-kommunikativnye strategii sovremennogo nauchnogo poznaniia. Moscow, Progress-Traditsiia Publ. 560 p. Pp. 350-367. (In Russ.)

Kagan, M. S. (2018) Chelovek v teorii kul'tury. Izbrannye trudy: posobie dlja vuzov. Moscow, Izdatel'stvo Jurajt. 195 p. (In Russ.)

Karsavin, L. P. (1993) Filosofiia istorii. St.-Petersburg, Komplekt Publ. 350 p. (In Russ.)

Cassirer, E. (2002) Filosofija simvolicheskib form. Tom 1. Jazyk. Moscow. St.-Petersburg, Universitetskaja kniga. 272 p. (In Russ.)

Knjazeva, E. N. (2015) Innovacionnaja slozbnost': metodologija organizacii slozbnyb adaptivnyb $i$ setevyb struktur. Filosofija nauki i tehniki. Vol. 20. no 2. Pp. 50-69. (In Russ.)

Leont'ev, K. N. (2003) Vizantizm i slavianstvo. Leont'ev, K. N. Khram i Tserkov'. Moscow. Izdatel'stvo AST Publ. 636 p. (In Russ.)

Lotman Iu. M. (1998) Struktura kbudozhestvennogo teksta. St.-Petersburg, Iskusstvo-SPB Publ. 704 p. (In Russ.)

Malinovskii, A. A. (2000) Tektologiia. Teoriia sistem. Teoreticheskaia biologiia. Moscow, Editorial URSS Publ. 448 p. (In Russ.)

Morin, E. Metod. Priroda Prirody (2005). Moscow, Progress-Tradicija. 464 p. (In Russ.)

Nazaretjan, A. P. (2013) Nelinejnoe budushbee. Moscow. MBA. 440 p. (In Russ.)

Ovodova, S. N. (2016) Antropokul'turnaja real'nost': ot paradoksa k proektu: monografija. Omsk. Izdatel'stvo Omskogo gosudarstvennogo universiteta. 190 p. (In Russ.)

Opolev, P. V. (2015) V poiskah subektivnoj slozhnosti: ot logosa k logeme. Vestnik Omskogo gosudarstvennogo pedagogicheskogo universiteta. Gumanitarnye issledovanija. no. 4 (8). Pp. 17-21. (In Russ.)

Opolev, P. V. (2018) Problemy opredeleniia antropokul'turnoi slozhnosti. Gumanitarnyi vestnik. no. 10 (72). Pp. 1-15. (In Russ.)

Ortega y Gasset José (2008) Vosstanie mass. Degymanizacija iskusstva. Beshrebetnaja Ispanija. Moscow, AST. 347 p. (In Russ.)

Pilipenko, A. A. (2015) Epistema slozhnosti i ee proiavleniia v kul'ture. Kul'tura kul'tury: elektronnyi zburnal. no. 2 (6). [online] Available at: http://cult-cult.ru/episteme-of-complexity-and-itsmanifestation-in-culture (accessed: 08.05.2019). (In Russ.)

Rickert, G. Nauki o prirode i nauki o kul'ture. Moscow, Respublika Publ. 413 p. (In Russ.)

Toynbee, A. (2010) Postizbenie istorii. Moscow, Airis-press Publ. 640 p. (In Russ.) Russ.)

Triandis, G. K. (2011) Kul'tura i sotsial'noe povedenie. Moscow, Forum Publ. 384 p. (In

Trubetskoi, N. S. (1995) Istoriia. Kul'tura. Iazyk. Moscow, Progress Publ. 799 p. (In Russ.)

Turgot, A. (1999) Progress chelovecheskogo razuma. Filosofiia i obshchestvo. no. 3. Pp. 160-167. (In Russ.)

Bargendordff, S. (2009) Simple Lives, Cultural Complexity. Retbinking Culture in Terms of Complexity Theory. Lanham MD: Lexington Books. 188 p.

Chao, T. G. Moon, H. (2005) The cultural mosaic: a metatheory for understanding the complexity of culture. Journal of Applied Psychology. Vol. 90. no. 60. Pp. 1128-1140.

Hodge, B. (2007) The Complexity Revolution. A Journal of Media and Culture. Vol. 10. [online] Available at: URL: http://journal.media-culture.org.au/0706/01-hodge.php (accessed: 08.05.2019). 
Ополев Павел Валерьевич - кандидат философских наук, доцент, доцент кафедры философии Сибирского государственного автомобильно-дорожного университета. Адрес: 644080, Россия, г. Омск, пр. Мира, А. 5. Тел.: +7 (3812) 65-33-54. Эл. адрес: pvo-sinergetica@rambler.ru

Opolev Pavel Valeryevich, Candidate of Philosophy, Associate Professor, Associate Professor, Department of Philosophy, Siberian State Automobile and Highway University. Postal address: 5, Mira Ave., Omsk, Russian Federation, 644080. Tel: +7 (3812) 65-33-54. E-mail: pvo-sinergetica@rambler.ru

DOI: $10.17805 /$ zpu.2019.4.13

\title{
Развитие взглядов на феномен «чужого» в истории культуры
}

\author{
М. А. ПОЛЕТАЕВА \\ МОСКОВСКИЙ ГОСУДАРСТВЕННЫЙ ЛИНГВИСТИЧЕСКИЙ УНИВЕРСИТЕТ
}

В статье дается обзор эволюции представлений о своем и чужом человеке в истории человечества. Это первая попытка комплексной научной систематизации типовых взглядов общества на эту проблему в истории, игравших значимую роль в становлении национальной идентичности людей.

В первую очередь рассматриваются различные варианты членения истории на периоды и обосновывается значимость ее членения на технологические эпохи: доиндустриальную, индустриальную и постиндустриальную. Развертываются нужные для данного исследования характеристики каждой эпохи и показывается, почему в каждую эпоху различалось отношение к дихотомии свой/чужой.

Для доиндустриальной эпохи было свойственно восприятие чужого как существа вредного, с которым следует иметь дело как можно меньше и реже контактировать. Чужой - это враг, порождение дьявола, и с ним всегда нужно быть настороже.

В индустриальную эпоху чужой воспринимался как человек, отличающийся от местного, но не опасный. Взаимодействовать с ним можно, особенно при его достаточной ассимиляции в местной среде.

В постиндустриальную эпоху чужой воспринимается уже лишь как культурно другой, но тем и интересный человек. Взаимодействие с ним возможно, так же как и со своим.

Таким образом, в истории имела место определенная эволюция отношения общества к чужому от его максимального отторжения к его преимущественному приятию.

Ключевые слова: свой; чужой; доиндустриальная эпоха; индустриальная эпоха; постиндустриальная эпоха; история культуры

\section{ВВЕАЕНИЕ}

$\Pi$ редставления о чужом были разными в разные эпохи. Особенности этих представлений в существенной мере определялись мировоззренческими характеристиками этих эпох, параметрами картин мира людей, живших в разное время. Поэтому, прежде чем приступать к рассмотрению особенностей такого отношения к чужим, нужно определиться с принципами членения истории на эпохи.

В мировой науке существует множество вариантов членения истории на различные периоды, созданные на протяжении многих веков и опирающиеся на разные основания. Это и социально-экономические формации, и культурно-цивилизационные эпохи, и религиозные эры, и т. п. Из этого множества вариантов мы выбираем сравни- 